\title{
DIFERENCIAÇÃO ENTRE OS VÍRUS DA RINOTRAQUEÍTE INFECCIOSA BOVINA (BHV-1) E HERPESVÍRUS DA ENCEFALITE BOVINA (BHV-5) COM ANTICORPOS MONOCLONAIS ${ }^{1}$
}

\author{
Paulo Michel Roehe ${ }^{2,3}$, Tamir Calcagnotto da Silva ${ }^{4}$, Nance Beyer Nardi ${ }^{5}$, Liliane \\ Guimarães Oliveira ${ }^{2}$ e Júlio César de Almeida Rosa²
}

\begin{abstract}
Roehe P.M., Silva T.C., Nardi N.B., Oliveira L.G. \& Rosa J.C.A. 1997. [Monoclonal antibody differentiation between bovine herpesviruses type 1 and 5.] Diferenciação entre os vírus da rinotraqueíte infecciosa bovina (BHV-1) e herpesvírus da encefalite bovina (BHV-5) com anticorpos monoclonais. Pesquisa Veterinária Brasileira 17(1):41-44. Centro de Pesquisas Veterinárias Desidério Finamor, Caixa Postal 2076, Porto Alegre, RS 90001-970, Brazil.

Bovine Herpesviruses (BHV) type 1 (BHV-1) and type 5 (BHV-5) were analysed by immunoperoxidase staining with a panel of monoclonal antibodies (Mabs) prepared against BHV antigens. One of the Mabs recognized all BHV isolates tested. The remainder four mabs recognized only BHV-1 samples, including standard laboratory strains. All isolates associated with clinical cases of encephalitis (BHV-5) displayed a pattern of reactivity distinct from that of viruses isolated from syndromes associated with BHV-1 infections. The results obtained indicate that such Mabs allowed the differentiation between BHV-1 and BHV-5, with a perfect correlation between the clinical pictures and the patterns of reactivity in vitro.
\end{abstract}

INDEX TERMS: Bovine herpesviruses, infectious bovine rhinotracheitis virus, IBR, IPV, bovine encephalitis virus, BHV-1, BHV-5.

SINOPSE.- Amostras de herpesvírus bovinos (BHV) tipo 1 (Virus da Rinotraqueíte Infecciosa Bovina/Vulvovaginite Pustular Infecciosa; BHV-1) e tipo 5 (Herpesvírus da Encefalite Bovina; BHV-5) tiveram seu perfil de reatividade analisado em testes de imunoperoxidase frente a um painel composto por cinco anticorpos monoclonais (AcM) produzidos contra antígenos de BHV-1. Um dos AcM reconheceu todas as amostras de BHV examinadas. Os quatro AcM restantes reconheceram somente amostras de BHV-1. Todas as amostras isoladas de casos

\footnotetext{
1 Aceito para publicação em 8 de janeiro de 1997.

Trabalho financiado pela Fundação de Amparo à Pesquisa do Estado do Rio Grande do Sul (FAPERGS) e pelo Conselho Nacional de Desenvolvimento Científico e Tecnológico (CNPq). Este assunto foi objeto da tese de Mestrado do segundo autor.

2 Fundação Estadual de Pesquisa Agropequária (FEPAGRO) - Equipe de Virologia, Centro de Pesquisas Veterinárias Desidério Finamor (CPVDF), Caixa Postal 2076, Porto Alegre, RS 90001-970.

${ }^{3}$ Depto Microbiologia, Universidade Federal do Rio Grande do Sul (UFRGS), Av. Sarmento Leite 500, Porto Alegre, RS 90050-170.

4 IRFA Biotecnologia Industrial Ltda, Estrada do Lami 6133, Belém Novo, Porto Alegre, RS 91780-120.

${ }^{5}$ Depto Genética, UFRGS.
}

de encefalites (BHV-5) apresentaram um padrão de reação distinto daquelas isoladas de outros síndromes associados à infecção pelo BHV-1. Os resultados obtidos indicam que os AcM avaliados permitem a diferenciação entre amostras de BHV-1 e BHV-5, havendo perfeita correlação entre os quadros clínicos observados com os perfis de reatividade obtidos in vitro.

TERMOS DE INDEXAÇÃO: Herpesvírus bovinos, rinotraqueíte infecciosa bovina, encefalite bovina, BHV-1, BHV-5.

\section{INTRODUCC̃̃O}

O Vírus da Rinotraqueíte Infecciosa Bovina/Vulvovaginite Pustular Infecciosa é presentemente denominado Herpesvírus Bovino tipo 1 (BHV-1), sendo um membro da família Herpesviridae, sub-família Alfaherpesvirinae (Porterfield 1989). Este vírus está associado a várias síndromes, tais como rinotraqueíte, vulvovaginite, balanopostite, conjuntivite e abortos (Kahrs 1977, Wyler et al. 1990, Weiblen 1992). O BHV1 está presente em forma enzoótica no Brasil há vários anos, com evidências sorológicas da infecção em virtualmente todos os locais onde foram pesquisadas (Wizigmann et al. 1972, Ikuno et al. 1982, 1984, Ravazollo et al. 1989, Rosa et al. 1992, Lovato et al. 1995, Vidor et al. 1995). Esporadicamen- 
te, o BHV-1 causa infeç̧ões clinicamente aparentes, com morbidade variável e mortalidade baixa ou nula (Weiblen et al. 1989, Weiblen 1992).

Por sua vez, o Herpesvírus da Encefalite Bovina ou Herpesvírus Bovino tipo 5 (BHV-5) causa infecções de baixa morbidade e alta mortalidade, caracterizadas por meningoencefalites em bovinos jovens, usualmente até 8 meses de idade (French 1962, Bulach \& Studdert 1990), podendo ocasionalmente afetar animais mais velhos. Até recentemente, amostras que hoje são consideradas BHV-5 eram consideradas subtipos do Herpesvírus Bovino tipo 1 (BHV-1) devido às extensas reações sorológicas cruzadas observadas entre ambos (soro anti-BHV-1 é capaz de neutralizar amostras de BHV5) (French 1962). No entanto, as diferenças epidemiológicas, genômicas e antigênicas destes dois vírus, além da associação do BHV-5 com encefalites, fizeram com que este último fosse reclassificado, recebendo então a denominação atual (Roizmann et al. 1992). Até o presente, não é possível precisar qual a prevalência de infecções pelo BHV-5, uma vez que não existem testes sorológicos capazes de diferenciar entre infecções por este vírus e o BHV-1. No entanto, evidências obtidas em nosso laboratório indicam que uma significativa proporção de animais suspeitos de infecções por BHV-1 foram de fato infectados pelo BHV-5 (Teixeira et al. 1996). Tal prevalência somente poderá ser avaliada com precisão quando testes capazes de distinguir inequivocamente entre estas infecções estejam disponíveis.

Em busca de testes capazes de distinguir entre estes dois vírus, o presente trabalho teve por objetivo examinar o perfil de reatividade de diversas amostras de BHV-1 e BHV-5 frente a um painel de anticorpos monoclonais (AcMs) preparados contra antígenos de BHV-1.

\section{MATERIAL E MÉTODOS}

\section{Amostras virais}

A amostra de BHV-1 "Oxford" (Dawson et al. 1962) foi obtida do Central Veterinary Laboratory, New Haw, Weybridge, Surrey, UK. A amostra Los Angeles (Madin et al. 1956) foi obtida do Instituto Nacional de Investigaciones Agropecuárias (INTA), Argentina. Ambas são amostras isoladas de casos de doença respiratória (rinotraqueíte) em bovinos. A amostra Colorado (Madin 1956) foi obtida do Centro Panamericano de Febre Aftosa (CPFA), Rio de Janeiro. Outras amostras de campo de BHV-1 e BHV-5 utilizadas foram isoladas no laboratório de virologia do Centro de Pesquisas Veterinárias Desidério Finamor (CPVDF). Ainda foram utilizadas amostras gentilmente cedidas pelo Dr. Rudi Weiblen (UFSM) e Dr. Telmo Vidor (UFPEL). Os estoques de vírus foram produzidos pela inoculação dos cultivos com uma multiplicidade de infecção entre 0,1 e 1,0 doses infectantes para cultivos celulares $50 \%\left(\mathrm{DICC}_{50}\right)$ por célula, os quais foram coletados quando o efeito citopatogênico (ECP) atingiu aproximadamente $90 \%$ da monocamada. Após esse período, os cultivos foram congelados a $-70^{\circ} \mathrm{C}$, clarificados por centrifugação a baixa velocidade e o sobrenadante dividido em alíquotas e estocado a $-70^{\circ} \mathrm{C}$ até o momento de uso.

\section{Células}

As amostras de vírus foram multiplicadas em células renais de bovino "Madin Darby Bovine Kidney" (MDBK). As células foram multiplicadas com uma taxa de divisão de 1:4 a 1:6 uma ou duas vezes por semana, seguindo técnicas usuais (Paul 1970). Todos os cultivos e soros utilizados durante o experimento foram testados previamente para assegurar a ausência de contaminação por herpesvírus bovinos e pestevírus, bem como para confirmar a inexistência de anticorpos contra BHV (dados não apresentados).

\section{Anticorpos monoclonais}

Os AcM aqui utilizados foram obtidos a partir da imunização de camundongos BALB-C com amostra Oxford (Dawson et al.1962) de BHV-1. Os detalhes da produção e caracterização dos AcM foram descritos em trabalho prévio (Silva 1995, Silva et al. 1996).

\section{Testes de imunoperoxidase}

As amostras de BHV foram testadas frente aos AcM pela técnica de imunoperoxidase ou IPX (Saunders 1977, Edwards et al. 1983, Heinlein et al. 1993), como segue: Células MDBK foram semeadas em placas de microtécnica de 96 orifícios a uma concentração de 2,5 a $3 \times 10^{4}$ células/orifício. As células das colunas pares foram mantidas como controles não infectados. As colunas ímpares foram infectadas com 100 DICC $_{50}$ de cada amostra a ser testada. Ao início do efeito citopático (ECP), as células foram fixadas com $20 \%$ de acetona em $0,01 \mathrm{M}$ PBS $\left(8,5 \mathrm{~g} \mathrm{NaCl} ; 1,55 \mathrm{~g} \mathrm{Na} \mathrm{HPO}_{4} .2 \mathrm{H}_{2} \mathrm{O} ; 0,2 \mathrm{~g}\right.$ $\mathrm{NaH}_{2} \mathrm{PO}_{4} ; \mathrm{H}_{2} \mathrm{O}$ q.s.p. $11 ; \mathrm{pH} 7,6$ ) e secas em estufa a $37^{\circ} \mathrm{C}$ por 4 horas. A seguir as placas foram reidratadas por $5 \mathrm{~min}$ com $100 \mu \mathrm{l}$ de líquido de lavagem (PBS com 0,5\% de Tween 80). Após, o reidratante foi removido e foram colocados $50 \mu \mathrm{l}$ dos respectivos AcM, previamente titulados e diluídos em líquido de diluição $(29,5 \mathrm{~g} \mathrm{NaCl} ; 1,55 \mathrm{~g}$ $\mathrm{Na}_{2} \mathrm{HPO}_{4} .2 \mathrm{H}_{2} \mathrm{O} ; 0,2 \mathrm{~g} \mathrm{NaH} \mathrm{PO}_{4} ; 0,5 \%$ Tween $80 ; \mathrm{H}_{2} \mathrm{O}$ q.s.p. $11 ; \mathrm{pH} 7,6$ ). Soro controle positivo (soro policlonal anti-BHV produzido em camundongo) e negativo (soro de camundongos normais) foram incluídos em cada teste. As placas foram então incubadas por $15 \mathrm{~min}$ a $37^{\circ} \mathrm{C}$. Após este período, foram executadas três lavagens com líquido de lavagem. A seguir, foi adicionado conjugado peroxidase/ anti-IgG de camundongo (DAKO) a uma diluição apropriada (tipicamente 1:300 em líquido de diluição), sendo as placas incubadas novamente por $15 \mathrm{~min}$ a $37^{\circ} \mathrm{C}$. A seguir as placas foram lavadas 3 vezes com líquido de lavagem, a prova foi revelada pela adição do substrato 3-amino-9-etilcarbazol (fórmula em anexo) adicionado de $0,03 \% \mathrm{H}_{2} \mathrm{O}_{2}$ como recomendado (Harlow \& Lane 1988). A reação antígeno-anticorpo específica foi evidenciada pela coloração carmim nas células infectadas.

\section{RESULTADOS}

Os resultados obtidos à caraterização de amostras de BHV-1 e BHV-5 com os AcMs produzidos são apresentados no Quadro 2. Pode-se observar que o AcM 2G5 reagiu com todas amostras testadas, incluindo amostras de BHV-1 e amostras de BHV-5. Os demais AcMs reagiram somente com amostras de BHV-1 (Quadro 2), incluindo tanto aquelas originárias de casos de doenças respiratória e reprodutiva (BHV-1.1) ou genital (BHV1.2). Nenhum dos cinco AcMs permitiu a distinção entre os subtipos BHV-1.1 e BHV-1.2.

\section{DISCUSSÃO}

O BHV-1 é um vírus que encontra-se presente em todas as regiões do mundo onde se pratica a bovinocultura. Sua presença no Brasil é reconhecida há vários anos, e suas carecterísticas epidemiológicas são igualmente bastante co- 
Quadro 1. Amostras de vírus (herpesvírus bovinos tipos 1 e 5) utilizadas no presente estudo

\begin{tabular}{|c|c|c|c|}
\hline Amostra & Quadro clínico & Origem & Referência \\
\hline Oxford & $\mathrm{IBR}^{\mathrm{a}}$ & CVL & Dawson et al. 1962 \\
\hline Los Angeles & IBR & INTA & Madin et al. 1956 \\
\hline Colorado & IBR & CPFA & Madin et al. 1956 \\
\hline SV $035^{b}$ & IBR & UFSM & Heinlein et al. 1993 \\
\hline SV $056^{\mathrm{b}}$ & IBR & UFSM & Heinlein et al. 1993 \\
\hline SV $453^{b}$ & IPV & UFSM & Canabarro et al. 1993 \\
\hline Retiro & Vulvovaginite & UFPel & $\#^{\mathrm{c}}$ \\
\hline EVI $014 / 94^{d}$ & Aborto & CPVDF & Gewehr et al. 1994 \\
\hline SV $136 / 88$ & Encefalite & UFSM & Heinlein et al. 1993 \\
\hline EVI $190 / 94^{d}$ & Encefalite & CPVDF & Gewehr et al. 1994 \\
\hline EVI 088/95 & Encefalite & CPVDF & $@^{\mathrm{e}}$ \\
\hline EVI $214 / 95$ & Encefalite & CPVDF & $@$ \\
\hline EVI $219 / 95$ & Encefalite & CPVDF & $@$ \\
\hline
\end{tabular}

a $\mathrm{IBR}=$ amostras de vírus BHV-1 isoladas de casos de rinotraqueíte; IPV= amostras de BHV-1 isoladas de casos de vulvovaginite pustular; Encefalite $=$ amostras de BHV-5 isoladas de casos de encefalite; $\mathrm{CVL}=$ Central Veterinary Laboratory, New Haw, Weybridge, Surrey, UK; INTA = Instituto de Investigaciones Agropecuárias, Argentina; $\mathrm{CPFA}=$ Centro Panamericano de Febre Aftosa, Rio de Janeiro RJ; UFSM=Laboratório de Virologia, Depto Microbiologia, Fac. Veterinária, Universidade Federal de Santa Maria, RS; $\mathrm{CPVDF}=$ Centro de Pesquisas Veterinárias Desidério Finamor, Eldorado do Sul, RS; UFPel= Laboratório de Virologia, Fac. Veterinária, Universidade Federal de Pelotas, RS.

b Amostras gentilmente cedidas pelo Dr. Rudi Weiblen

c \# Amostras gentilmente cedidas pelo Dr. Telmo Vidor

d Instituto Nacional de Investigações Agropecuárias, Argentina, proveniente do Mato Grosso do Sul.

e @ Amostras isoladas no Centro de Pesquisas Veterinárias Desidério Finamor (CPVDF): registros de diagnósticos realizados (dados não publicados).

Quadro 2. Perfís de reatividade de amostras de herpesvírus bovinos tipos 1 (BHV-1) e 5 (BHV-5) em testes de imunoperoxidase frente a anticorpos monoclonais (AcM) produzidos contra antígenos de BHV-1

\begin{tabular}{lllllll}
\hline \multirow{2}{*}{$\begin{array}{c}\text { Amostras } \\
\text { de vírus }\end{array}$} & $\begin{array}{c}\text { Tipo/ } \\
\text { subtipo }\end{array}$ & \multicolumn{5}{c}{ Anticorpos monoclonais (AcM) } \\
\cline { 2 - 7 } Oxford & & $2 \mathrm{G} 5$ & $5 \mathrm{~A} 5$ & $7 \mathrm{~F} 12$ & $10 \mathrm{C} 4$ & $11 \mathrm{H} 6$ \\
\hline L.A. & BHV-1.1 & $+{ }^{\mathrm{b}}$ & + & + & + & + \\
Cooper & BHV-1.1 & + & + & + & + & + \\
EVI 014/94 & BHV-1.1 & + & + & + & + & + \\
SV 35/90 & BHV-1.1 & + & + & + & + & + \\
SV 56/90 & BHV-1.1 & + & + & + & + & + \\
SV 453/93 & BHV-1.1 & + & + & + & + & + \\
Retiro & BHV-1.2 & + & + & + & + & + \\
SV 136/88 & BHV-1.2 & + & + & + & + & + \\
EVI 190/93 & BHV-5 & + & $-c$ & - & - & - \\
EVI 088/95 & BHV-5 & + & - & - & - & - \\
EVI 214/95 & BHV-5 & + & - & - & - & - \\
EVI 219/95 & BHV-5 & + & - & - & - & - \\
\hline a $=$ Subtipo provável, de acordo com o caso clínico de origem. & \\
b + = Reação positiva com o AcM. & & & & & \\
c - = Reação negativa com o AcM. & & & & &
\end{tabular}

nhecidas (Gibbs \& Rweyemamu 1977). Já o BHV-5 apresenta particularidades em sua epidemiologia ainda pouco estudadas. Este último é o agente causal de encefalites quase que invariavelmente fatais em bovinos jovens, sendo responsável por expressiva mortalidade, notadamente na região central do Brasil (R. Amaral Lemos, comunicação pessoal). No entanto, a avaliação epidemiológica da extensão e importância das infecções por BHV-5 no mundo todo só poderá ser realizada quando se tornar possível a diferenciação entre infecções causadas por estes dois vírus, de uma maneira simples e prática.

Os AcMs aqui utilizados na caracterização das amostras de vírus foram produzidas contra antígenos de BHV-1 (Silva 1995). Não obstante, os resultados revelam que as amostras de BHV-1 originárias de casos de rinotraqueíte, vulvovaginite e abortos, puderam ser diferenciadas daquelas de BHV-5, obtidas de casos de encefalite. O AcM 2G5 reagiu à IPX com todas amostras de vírus testadas, enquanto que outros quatro AcMs (5A5, 7F12, 10C4 e 1lH6) reagiram somente com amostras de BHV-1, não reconhecendo amostras de BHV-5. Embora não tenha ainda sido possível determinar quais as proteínas reconhecidas pelos AcMs aqui empregados, podese afirmar que o AcMs $2 \mathrm{G} 5$ reconhece um epitopo comum a amostras de BHV-1 e BHV-5, enquanto que os demais só reconhecem epitopos presentes em amostras de BHV-1. Estudos futuros serão realizados com vistas a determinar qual a especificidade desses AcMs.

Testes capazes de detectar diferenças entre amostras de BHV-1 e BHV-5 já vinham sendo desenvolvidos previamente. No entanto, estes apresentavam o inconveniente de requerer análises antigênicas (Collins et al. 1993) e moleculares (Friedli \& Metzler 1987), muitas vezes caras ou inacessíveis a laboratórios de diagnóstico virológico. O teste aqui empregado permitiu a diferenciação entre os vírus de forma inequívoca, sendo que houve uma concordância de $100 \%$ entre os quadros clínicos de origem das amostras e os perfís de reatividade obtidos. A adaptação da técnica de IPX com AcMs para caracterização de amostras de herpesvírus bovinos apresentou como principal vantagem o fato desta ser simples e rápida, utilizando somente instrumentação básica, comum em laboratórios de diagnóstico virológico. Além disso, permite que em apenas uma placa de microtécnica o perfil de reatividade das amostras virais seja analisada frente a um painel formado por diferentes AcMs.

Agradecimentos.- Ao Dr. Ricardo Lemos Amaral, UFMS, pelo envio de amostras ao laboratório para isolamento de vírus.

\section{REFERÊNCIAS}

Bulach D.M. \& Studdert M.J. 1990. Comparative genome mapping of bovine encephalitis herpesvirus, bovine herpesvirus 1 , and buffalo herpesvirus. Arch. Virol. 113:17-34.

Canabarro T.F., Moraes M.P., Rebelatto M.C., Cancian N.D. \& Weiblen R. 1993. Vulvovaginitis due to Bovine Herpesvirus. Virológica 93, Soc. Bras. Virologia, Porto Alegre, p. 248. (Resumo)

Collins J.L., Ayres V.K., Whetstone C.A. \& van Drunen Littel-van den Hurk S. 1993. Antigenic differences between the major glycoproteins of bovine herpesvirus type 1.1 and encephalitis hervirus type 1.3. J. Gen. Virol. 74:1509-1517.

Dawson P.S., Darbyshire J.H., Loosmore R.M., Patterson A.B. \& Faull W.B. 1962. Infectious bovine rhinotracheitis (IBR). A clinical condition of cattle occurring in the United Kingdom. Vet. Rec. 74 (49):1379-1383. 
Edwards S., Chasey D. \& White H. 1983. Experimental infectious bovine rhinotracheitis: comparison of four antigen detection methods. Res. Vet. Sci. 34:42-45.

French E.L. 1962. A specific virus encephalitis in calves: isolation and characterization of the causal agent. Aust. Vet. J. 38:216-221.

Friedli K. \& Metzler A.E. 1987. Reactivity of monoclonal antibodies to proteins of a neurotropic bovine herpesvirus 1 (BHV-1) strain. Arch. Virol. 94:109122.

Gewehr V.R., Oliveira L.G. \& Roehe P.M. 1994. Isolamento de herpesvirus bovino tipo 1 (BHV-1) de casos de aborto e encefalite. VI Salão de Iniciação Científica da UFRGS, Porto Alegre, p. 94

Gibbs E.P.J. \& Rweyemamu M.M. 1977. Bovine herpesviruses. Part. I. Bovine herpesvirus 1. Vet. Bull. 47(5): 317-343.

Harlow E. \& Lane D. 1968. Antibodies: A Laboratory Manual. Cold Spring Harbour Laboratory. 726 p.

Heinlein A., Metzler A. E., Weiblen R., Berrios P., Schudel A. A. \& Rodriguez M. 1993. Molecular characterization of South American bovine herpesvirusisolates with monoclonal antibodies and SDS-PAGE. J. Vet. Med. B 40:125130 .

Ikuno A. A., Machado J. S. \& Mueller S. B. K. 1982. Levantamento sorológico da prevalência da rinotraqueíte infecciosa/vulvovaginite pustular infecciosa (IBR/IPV) em uma amostragem de bovinos de leite no estado de São Paulo. Revta Bras. Med. Vet. 5(3):34-38.

Ikuno A. A., Machado J. S., Mueller S. B. K., Ribeiro L. O. C. \& Chiba S. 1984. Presença de anticorpos contra o vírus da rinotraqueíte infecciosa dos bovinos/vulvovaginite pustular infecciosa (IBR/IPV) em búfalos (Bubalus bubalis) do estado de São Paulo. Biológico 50 (6):131-138.

Kahrs R. F. 1997. Infectious Bovine Rinotracheitis: a review and update. J. Am. Vet. Med. Assoc. 171(10): 1055-1064.

Lovato L.T., Weiblen R., Tobias F.L. \& Moraes M.P. 1995. Herpesvírus bovino tipo 1 (BHV-1): inquérito soro-epidemiológico no rebanho leiteiro no estado do Rio Grande do Sul, Brasil. Ciência Rural 25(3):425-430.

Madin S.H., York C.J. \& McKercher D.G. 1956. Isolation of the infectious bovine rhinotracheitis virus. Science 129:721-722.

Paul J. 1970. Cell and Tissue Cultures. 4th ed. E. \& S. Livingstone, Edinburgh. $380 \mathrm{p}$.

Porterfield J.S. 1989. Andrewes's Viruses of Vertebrates. 5 ed. Baillière Tindall, London, p. 293-332.
Ravazollo A.P., Dal Pizzol M. \& Moojen V. 1989. Evidência da presença de anticorpos para o vírus da rinotraqueíte infecciosa dos bovinos em alguns municípios do estado do Rio Grande do Sul. Arq. Fac. Vet. UFRGS 17:98-95.

Roizmann B., Desrosiers R.C., Fleckenstein B., Lopez C., Minson A.C. \& Studdert M.J. 1992. The family Herpesviridae: an update. Arch. Virol. 123: 425-448.

Rosa J.A., Bangel E.V., Martins R.M., Oliveira L.G. \& Roehe P.M. 1992. Anticorpos contra o vírus da rinotraqueíte infecciosa bovina (IBR) em bovinos no Rio Grande do Sul. Anais $11^{\circ}$ Congr. Est. Med. Vet., Gramado, RS. SOVERGS, p. 86.

Saunders G.C. 1977. Development and evaluation of an enzyme-labeled antibody test for rapid detection of hog cholera antibodies. Am. J. Vet. Res. 38(1): 21-25.

Silva T.C. 1995. Produção e caracterização de anticorpos monoclonais contra o herpesvírus bovino tipo 1 (BHV-1). Tese de Mestrado, Fac. Med. Vet. UFRGS, Porto Alegre.

Silva T.C., Roehe P.M., Nardi N.B. \& Oliveira L.G. 1996. Produção e caracterização de anticorpos monoclonais contra o vírus da rinotraqueíte infecciosa bovina (BHV-1) Arq. Bras. Med. Vet. Zootec. (Submetido)

Teixeira M.B., Roehe P.M., Coelho C.S.S., Teixeira J.C., Rosa J.C.A. \& Silva T.C. 1996. Comparação entre níveis de anticorpos contra herpesvírus bovinos tipos 1 (BHV-1) e 5 (BHV-5) em soros bovinos pela técnica de soroneutralização. Anais VIII Encontro Nacional de Virologia, 24-27 nov., São Lourenço, MG. (No prelo)

Vidor T., Halfen D.C., Leite T.E. \& Coswig L.T. 1995. Herpesvírus bovino tipo 1 (BHV-1). I. Sorologia de rebanhos com problemas reprodutivos. Ciência Rural 25(3):421-424.

Weiblen R., Barros C. S. L., Canabarro T. F. \& Flores I.E. 1989. Bovine meningoencephalitis from IBR virus. Vet. Rec. 124:666-667.

Weiblen R. 1992. Doenças víricas que interferem na produção leiteira, p. 4562. In: Charles T.P. \& Furlong J. (ed.) Doenças dos Bovinos de Leite Adultos. Embrapa - CNPGL, Coronel Pacheco, MG.

Wizigmann G., Vidor T. \& Ricci Z.M. 1972. Investigações sorológicas sobre a ocorrência e incidência dos vírus PI-3, IBR e diarréia a vírus enfermidade das mucosas dos bovinos no estado do Rio Grande do Sul. Bolm Inst. Pesq. Vet. Desidério Finamor, Porto Alegre, 1:52-58.

Wyler R., Engels M. \& Schwyzer M. 1990. Infectious Bovine Rhinotracheitis/ Vulvovaginitis (BHV-1), p.1-71. In: Wittman, G. (ed.). Herpesvirus Diseases of Cattle, Horses and Pigs. Kluwer Academic Publishers, Norwell. 